\title{
Notícias/News
}

\section{EPIDEMIOLOGISTAS SE POSICIONAM CONTRA ARMAS NUCLEARES}

Cerca de 1.000 epidemiologistas especializados na área de cardiologia, representantes de 67 países, manifestaram-se em apoio ao Apelo feito pela "International Physicians of Nuclear War", dirigido aos lideres de cinco nações que atualmente possuem armas nucleares. Este Apelo, a seguir apresentado, foi dirigido no sentido de que se termine com as armas nucleares, pelos malefícios que podem causar.

"A guerra nuclear tem sido chamada de epidemia final. Todos aqueles que têm dedicado sua vida aos trabalhos de epidemiologia e prevenção das doenças cardiovasculares - para criar uma base científica para prevenção de doenças epidêmicas nesse campo - estão profundamente preocupados com o contínuo crescimento das armas nucleares que podem levar a esta epidemia final. Nós que nos dedicamos à prevenção devemos fazer o que for humanamente possível para prevenir este holocausto".

Os epidemiologistas que apoiaram este Apelo são dos seguintes países:

África do Sul
Argentina
Austrália
Austria
Barbados
Bélgica
Brasil
Bulgaria
Canadá
Colômbia
Coréia
Cuba
Dinamarca
Escócia
Espanha
Estados Unidos da
América
Etiópia
Filipinas
Finlândia
França
Grécia
Holanda
Hong Kong

Hungria
India
Indonésia
Inglaterra e País
de Gales
Ioguslávia
Irlanda
Israel
Itália
Japão
Kenia
Kuwait
Libéria
Malta
México
Moçambique
Nepal
Nigéria
Noruega
Nova Zelândia
Papua - Nova Guiné
Paquistão
Polônia
Portugal

República Democrática

Alemã

República Federal

Alemã

República Popular

da China

República Soviética

Rumênia

Sudão

Suriname

Suécia

Suissa

Síria

Tanzânia

Tasmânia

Tchecoslováquia

Tailândia

Trinidad

Tunísia

Turquia

Uganda

Zaire

Zambia

Zimbabwe 


\section{PESQUISA EPIDEMIOLÓGICA EM HANSENIASE}

As Áreas de Dermatologia Sanitária e de Estatística do Departamento de Epidemiologia da Faculdade de Saúde Pública da Universidade de São Paulo estão iniciando o desenvolvimento, em colaboração com o Département d'Epidémiologie de l'École de Santé Publique de l'Université Catholique de Louvain (Centro de Referência da OMS para Epidemiologia da Hanseníase), de uma linha de pesquisa epidemiológica que se realizará utilizando dados provenientes dos Arquivos de Hanseníase da Divisão de Hansenologia e Dermatologia Sanitária do Instituto de Saúde da Secretaria da Saúde do Estado de São Paulo.

Neste trabalho, objetiva-se a aplicação de metodologia epidemiológica analítica habitualmente utilizada em moléstias crônico-degenerativas (estudos de coortes, casos-controle, etc.), para melhor conhecimento do quadro epidemiológico da hanseníase em nosso meio.

Alguns resultados preliminares deste trabalho, como por exemplo a análise da tendência temporal num período de 50 anos (1931 a 1980) de algumas variáveis como a idade do paciente no diagnóstico, a idade do paciente no óbito e o tempo de duração da doença antes do diagnóstico foram apresentados no II Congresso de Hansenologia dos Países Endêmicos, realizado em Carville, Estados Unidos, em dezembro de 1985. 